\title{
PATRIMÔNIO, CULTURA E LUGAR: REFLEXÕES SOBRE A FESTA DE SÃO BENEDITO EM BRAGANÇA-PA ${ }^{1}$
}

\begin{abstract}
Alessandra Silva LOBATO
Resumo

O presente artigo tem como objetivo analisar a Festa de São Benedito em Bragança como um elemento representativo do patrimônio e cultura do lugar. Trata-se de uma revisão de literatura sobre a Festa de São Benedito e a Marujada bragantina baseado em trabalhos como de Bordallo da Silva (1981), Silva (1997), Nonato da Silva (2006), Carvalho (2010). Discute-se, também, sobre patrimônio, a partir de Canclini (1994), Meneses (1994) e Paes (2009); e cultura, tendo por base Laraia (2001), e sobre lugar, utilizando os trabalhos de Tuan (1983) e Santos (2008). Na ocasião, realizou-se trabalho de campo para observar as dinâmicas sociais e culturais que envolvem a festa. Observou-se que a Festa de São Benedito é a maior se comparada com a da padroeira da cidade Nossa Senhora do Rosário, pois durante as entrevistas foi unânime os entrevistados afirmarem que São Benedito consegue reunir um número superior de devotos durante o período da festa. É uma importante expressão cultural e patrimonial, que vem sendo passada de geração em geração, através das expressões culturais, ritos, rituais, danças, fé e devoção. Concluiu-se que há uma forte relação econômica, mas também social e cultural entre o patrimônio e a cultura em Bragança, haja vista que a Festa de São Benedito, e em especial a Marujada, promove uma relação de identidade de parte da população com o lugar.
\end{abstract}

Palavra-chave: Bragança. São Benedito. Patrimônio. Lugar.

\begin{abstract}
O presente artigo tem como objetivo analisar a Festa de São Benedito em Bragança como um elemento representativo do patrimônio e cultura do lugar. Trata-se de uma revisão de literatura sobre a Festa de São Benedito e a Marujada bragantina baseado em trabalhos como de Bordallo da Silva (1981), Silva (1997), Nonato da Silva (2006), Carvalho (2010). Discute-se, também, sobre patrimônio, a partir de Canclini (1994), Meneses (1994) e Paes (2009); e cultura, tendo por base Laraia (2001), e sobre lugar, utilizando os trabalhos de Tuan (1983) e Santos (2008). Na ocasião, realizou-se trabalho de campo para observar as dinâmicas sociais e culturais que envolvem a festa. Observou-se que a Festa de São Benedito é a maior se comparada com a da padroeira da cidade Nossa Senhora do Rosário, pois durante as entrevistas foi unânime os entrevistados afirmarem que São Benedito consegue reunir um número superior de devotos durante o período da festa. É uma importante expressão cultural e patrimonial, que vem sendo passada de geração em geração, através das expressões culturais, ritos, rituais, danças, fé e devoção. Concluiu-se que há uma forte relação econômica, mas também social e cultural entre o patrimônio e a cultura em Bragança, haja vista que a Festa de São Benedito, e em especial a Marujada, promove uma relação de identidade de parte da população com o lugar.
\end{abstract}

Keyword: Bragança. St. Benedict. Patrimony. Place.

\section{INTRODUÇÃO}

Tratar sobre patrimônio e cultura a partir da análise de uma Festa não é tarefa fácil. Ao observar as dimensões e proporções alcançadas pela Festa de São Benedito em Bragança, no estado do Pará, faz-se necessária uma reflexão mais aprofundada sobre esta manifestação que é ao mesmo tempo religiosa e cultural, e que influencia a dinâmica social e econômica do lugar, como pôde ser constatado durante o trabalho de campo. Assim, busca-se refletir sobre

\footnotetext{
${ }^{1}$ Artigo apresentado no Seminário 45 Anos do Núcleo de Altos Estudos da Amazônia, Belém, 2018.

Revista do Instituto Histórico e Geográfico do Pará (IHGP), (ISSN: 2359-0831 - online), Belém, v. 05, n. 02, p. 140-155, jul./dez. 2018.
} 
alguns aspectos que envolvem a construção de uma festa religiosa e cultural no interior da Amazônia oriental, que resiste há séculos, mesmo diante da modernização do espaço.

Bragança é uma cidade localizada acerca de duzentos quilômetros da capital, Belém, no nordeste do estado do Pará, mapa 01. É uma cidade de fácil acesso pelas rodovias, entretanto, nem todo tempo foi dessa forma.

Mapa 01: Localização do município de Bragança, Pará, Brasil

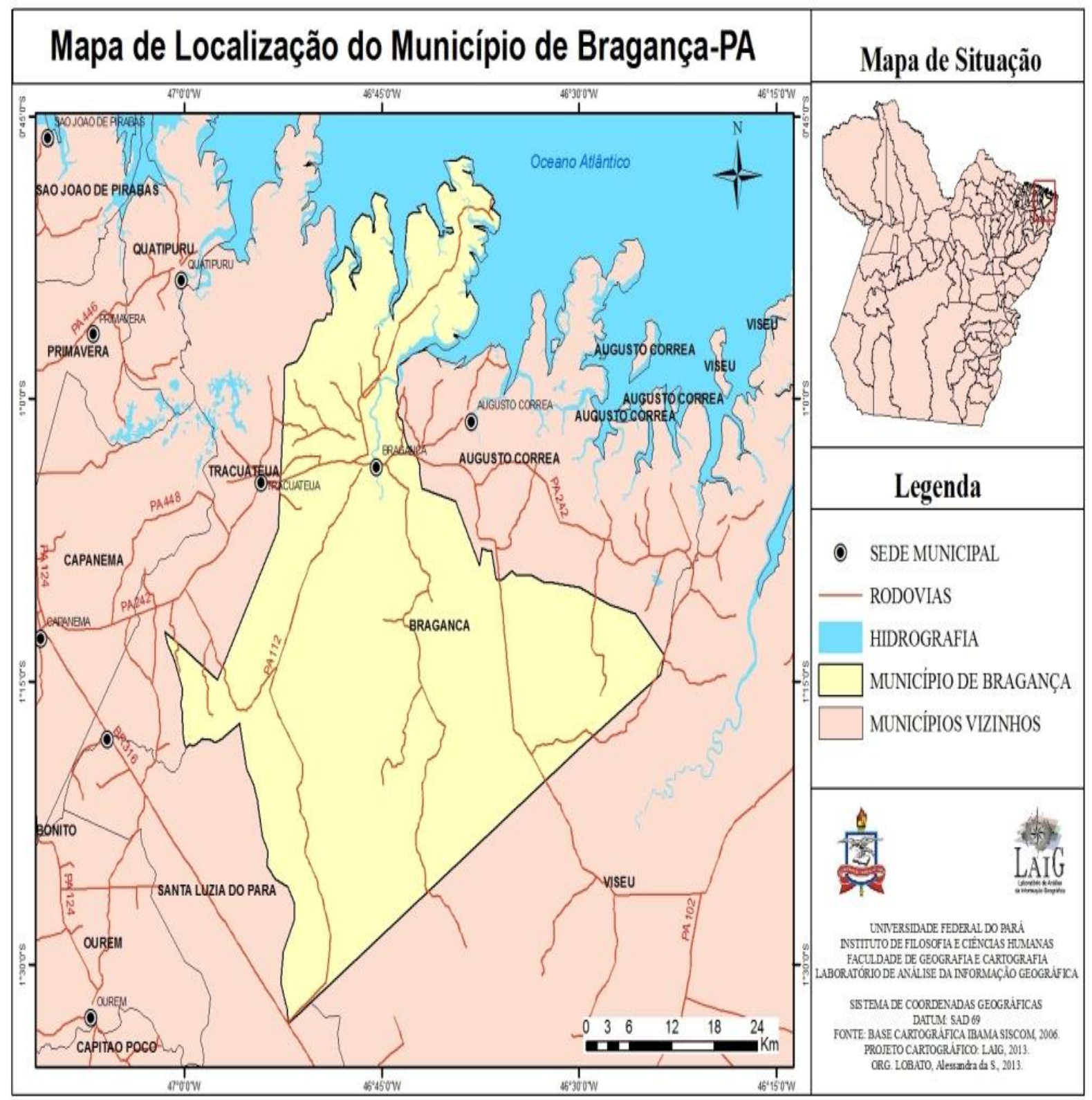

Fonte: LOBATO, 2014. 
Trata-se de uma das cidades mais antigas do estado Pará. Observe a figura 01, nela é possível identificar uma das primeiras plantas da cidade de Bragança. Nas figuras 02 e 03 nota-se a parte frontal da cidade na década de $1950 \mathrm{com}$ as palmeiras imperiais e os primeiros trapiches. Bragança é uma cidade que ainda possui muitos resquícios do passado que permanecem na paisagem. Documentos históricos apontam que a colonização dessa região iniciou ainda no século XVII com as expedições de exploração que saíram do estado do Maranhão em direção ao rio Amazonas, na região norte do Brasil, como apontou Nonato da Silva (2006).

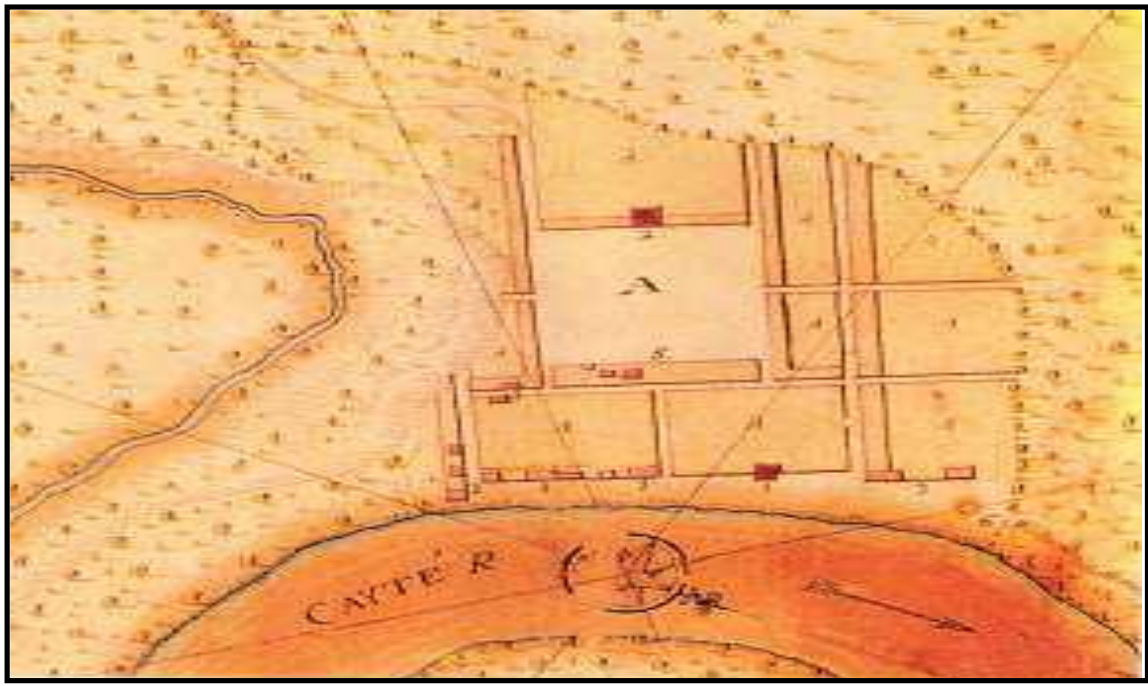

Figura 01. Planta da Vila Nova de Bragança: detalhe dos rios Guajará e Cayté. Original matnuscrito de E. Galuzzi, do Arquivo Histórico do Exército (Rio de Janeiro, 1754). (Fonte: REIS, N. Goulart. Imagens de Vilas e Cidades do Brasil Colonial, p. 280).

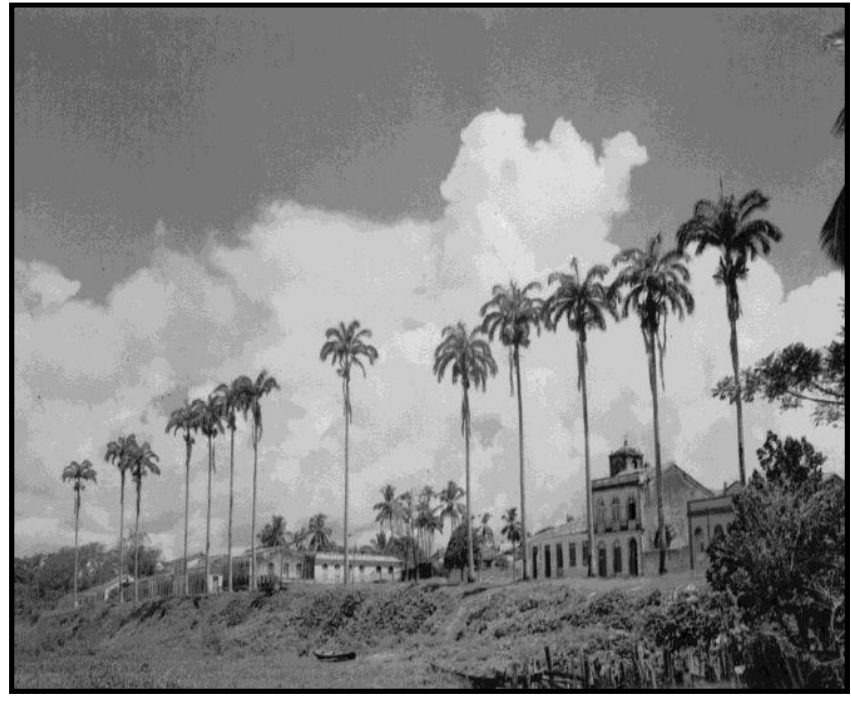

Figura 02. Visão frontal da parte mais elevada da cidade de Bragança: presença de palmeiras imperiais, década de 1950 (Fonte: Biblioteca Digital do IBGE. Disponível em: http://biblioteca.ibge.gov.br/visualizacao/fotografias/GEB IS\%20-\%20RJ/PA8604.jpg). Acesso: 20 de outubro de 2013.

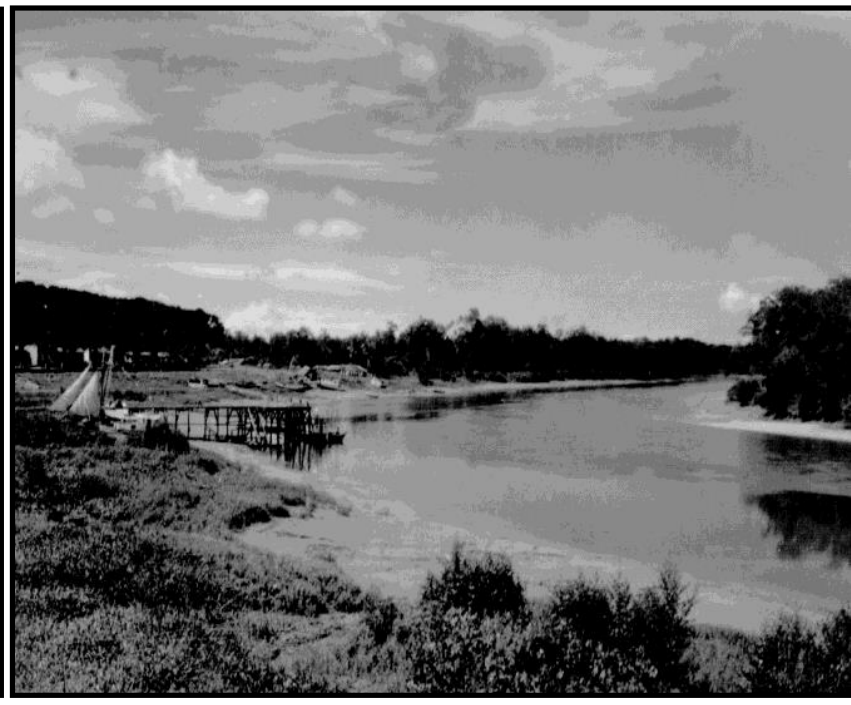

Figura 03. Visão frontal de parte da cidade de Bragança: o rio Caeté e um dos trapiches, década de 1950 (Fonte: Biblioteca Digital do IBGE. Disponível em: http://biblioteca.ibge.gov.br/visualizacao/fotografias/GEBI S\%20-\%20RJ/PA8607.jpg). Acesso: 20 de outubro de 2013. 
Bragança é uma cidade que ainda possui resquícios dos séculos passados, que retratam os vários momentos que contribuíram para o processo de produção do espaço. São casarões antigos, palacete, coreto, igrejas históricas, praças, rugosidades espaciais (SANTOS, 2008) que permanecem na paisagem bragantina decorrentes da influência dos indígenas, negros e, também, dos colonizadores que chegaram à cidade, inicialmente, pelo rio Caeté e, posteriormente, pela antiga Estrada de Ferro Bragança, e que remontam, também, ao período áureo da economia da borracha na região.

É possível observar que há forte relação de parte da população com as manifestações culturais e religiosas praticadas pela população local. Entre elas, destaca-se uma das mais tradicionais e representativas do ponto de vista social, cultural e econômico: a Festa de São Benedito, no qual se apresenta a Marujada de São Benedito. Festa que no ano de 2018 completou 220 anos de história e tradição, e que tem sido repassada de geração em geração. Trata-se de uma festa que se faz resistente ao tempo, às intempéries e transformações ocasionadas pela vida moderna.

Tendo em vista essas observações, o presente trabalho busca investigar como a Festa de São Benedito é um elemento representativo do patrimônio e da cultura bragantina no nordeste paraense.

Esta pesquisa fundamentou-se em uma revisão de literatura sobre a Festa de São Benedito e a Marujada bragantina pensada a partir de uma perspectiva religiosa, cultural e patrimonial. Para isso, a pesquisa baseou-se em trabalhos de Bordallo da Silva (1981), Silva (1997), Nonato da Silva (2006), Carvalho (2010). Discute-se, também, sobre a categoria lugar na perspectiva da ciência geográfica baseada nos trabalhos de Tuan (1983) e Santos (1988; 2005; 2008); sobre patrimônio, utilizando os trabalhos de Canclini (1994), Meneses (1992)e Paes (2009),e sobre cultura, com o trabalho de Roque Laraia (2001), os quais serão base para as reflexões que visam um entendimento dessas dinâmicas culturais, sociais, patrimoniais a partir da análise da Festa de São Benedito pelo olhar da geografia. Durante a pesquisa, realizou-se um levantamento iconográfico, no qual foi possível ter acesso a imagens antigas da cidade.

Foram utilizados, também, dados coletados durante o período do mestrado da autora, realizado entre os anos de 2012 a 2014.Além disso, foi realizado um trabalho de campo no mês de dezembro de 2018, mais precisamente entre os dias 18 a 26, período auge da Festa de São Benedito em Bragança. Neste trabalho de campo foram aplicados alguns questionários 
com marujos e marujas e turistas. Realizou-se, também, algumas entrevistas semiestruturadas com representantes da secretaria de cultura e turismo do município, observações in loco e registros fotográficos.

$\mathrm{O}$ artigo está estruturado em duas partes. Na primeira, discute-se sobre a relação entre o patrimônio, a cultura e o lugar. Na segunda, analisa-se propriamente a Festa de São Benedito e a Marujada bragantina como elementos culturais e patrimoniais da particularidade do lugar, a partir das reflexões discutidas no desenvolvimento teórico e da análise dos dados obtidos no trabalho de campo.

\section{PATRIMÔNIO, CULTURA E LUGAR: ALGUMAS CONSIDERAÇÕES}

Analisar patrimônio e cultura requer a compreensão que estes elementos apresentam ligações e conexões, principalmente, quando se analisa as particularidades de um lugar. $\mathrm{O}$ patrimônio, a princípio, pode ser entendido como aquilo que as pessoas, físicas ou jurídicas, possuem de valor - seus bens, posses, aquilo que se deixa como legado para seus descendentes (MACHADO e PIRES, 2012). No entanto, a interpretação pelo viés individual e econômico não é a única forma de compreender o conceito, que precisa ser analisado em sua complexidade, levando em consideração as particularidades, especificidades e a imaterialidade presente no lugar.

Para Paes (2009), uma das formas mais recorrentes para se interpretar o patrimônio remete à história sociocultural que deve ser preservada. Essa necessidade conduz à compreensão das dimensões cultural, técnica e política.

Cultural, porque somos nós, homens, no exercício da cultura, que elegemos o que deve ser preservado, imprimindo uma dimensão valorativa aos bens materiais ou intangíveis. Técnica, pois devemos desenvolver saberes, instrumentos e normas para levar a termo o processo de preservação. Política, porque esta seleção e normatização dos bens que devem ser patrimonializados envolvem ações e decisões, resultantes de conflitos de interesses, que devem ser normatizadas - o tombamento é, assim, uma ação cultural, técnica e política (PAES, 2009, p. 163-164).

Neste sentido, a patrimonialização abarca "um conjunto de práticas sociais, desde as mais diversas formas de produção cultural, de saberes simbólicos e técnicos, até os inúmeros processos de institucionalização do patrimônio como tal, que permitem a preservação dos bens culturais" (PAES, 2009, p. 164). Tratar de questões voltadas a esse tema requer o entendimento de que esse processo é conflituoso e contraditório na produção do espaço. 
O patrimônio cultural envolve, também, a compreensão de valores. É necessário interpretá-lo como um fenômeno social, "sempre vinculado a um espaço e tempo específicos é preciso entender também historicamente as formas de sociabilidade, que são extremamente variáveis" (MENESES, 1992, p. 189). Nesse sentido, o patrimônio deve ser entendido não apenas como elemento formador do espaço, mas sim como elemento que se constitui em um espaço e que, através do tempo, permite produzir no espaço marcas do passado, tanto pelas formas como pelas relações que foram estabelecidas ao longo do tempo, relações essas que envolvem significados, sentidos para aquele determinado grupo naquele lugar.

De acordo com Meneses (1992) o centro de qualquer apreensão referente ao patrimônio cultural é "político por natureza". Essa dimensão política é expressa como um elemento significativo porque revela que o patrimônio tem seu papel no processo de produção do espaço geográfico.

Nota-se, também, que há necessidade de que a população local perceba os patrimônios como sendo parte de suas identidades e que participem das ações voltadas ao desenvolvimento do turismo nas cidades e nas políticas ligadas à preservação do patrimônio, pois "as políticas culturais não deveriam ser, como ocorre, diretrizes e estratégias para ação de órgãos e áreas culturais e respectivos públicos” (MENESES, 1992, p. 95), ou seja, elas devem ir muito além.

As sociedades de massa e a indústria cultural ainda tratam a "cultura como um mecanismo de segregação e fragmentação e circunscreve seu raio de ação balizado por produtos, produtores, órgãos, lugares e equipamentos culturais" (MENESES, 1992, p. 95). A cultura torna-se, cada vez mais, um elemento de comercialização e espetacularização. Isto revela que tais processos nem sempre significam que o patrimônio está sendo devidamente preservado. Entretanto, há casos em que o patrimônio realmente tem sido preservado e que essa ação partiu da própria população, como é o caso da Festa de São Benedito em Bragança.

Observa-se, ainda, que o patrimônio cultural em seu conjunto "expressa a solidariedade que une os que compartilham um conjunto de bens e práticas que os identifica, mas também costuma ser um lugar de cumplicidade social" (CANCLINI, 1994, p. 96). Ele admite identificar as diferenças entre os grupos sociais e a superioridade dos que gozam de um ingresso preferencial à produção e distribuição de bens, como ressaltou Canclini (1994).

Assim, no processo de interpretação do patrimônio, é importante ter em vista que se trata de um espaço de disputa econômica, política e simbólica, atravessado pela ação de três 
tipos de agentes: o Estado, o setor privado e os movimentos sociais (CANCLINI, 1994). Cada um desses agentes produz sua interpretação, de forma que "as contradições no uso do patrimônio tem a forma que assume a interação entre estes setores em cada período" (Idem, 1994, p. 100). Além disso, é preciso entender como o patrimônio é interpretado, haja vista que envolve não somente as formas do passado, mais também o conjunto de manifestações culturais que fazem parte do lugar como as festas culturais, religiosas, os ofícios, entre outros. Assim, ao longo do tempo, percebe-se que o patrimônio se tornou um elemento de disputa e apropriação pelos diversos agentes que passam a imprimir nestes valores, sentidos e significados de acordo com seus interesses que podem ser para reforçar suas culturas, mas que também pode ser para mercantilizar essa expressão cultural do lugar com o intuito de articular as outras escalas seja ela regional ou mesmo global.

Ressalta-se que o patrimônio "não inclui apenas a herança de cada povo, as expressões "mortas" de sua cultural, mas também os bens culturais visíveis e invisíveis" (CANCLINI, 1994, p. 96). Pensando o caso de Bragança, vemos que é a igreja, é o Santo, é o arraial da Festa de São Benedito, mais são, também, as relações sociais, culturais e econômicas (porque não?) que se estabelecem diante da Festa, os laços afetivos, a devoção, os rituais que compõem o lugar. Nesse sentido entende-se que os lugares têm muitos significados que são atribuídos pelas pessoas e traduz os espaços com os quais as pessoas têm vínculos mais afetivos e subjetivos que racionais e objetivos (TUAN, 1983). Apesar disso, não se pode descartar a necessidade de entender como os lugares se articulam as outras escalas de análise, já que tratar sobre Festa e, em particular, a Festa de São Benedito, requer a compreensão das relações econômicas e sociais que se estabelecem enquanto ela ocorre, pois é visível o aumento do fluxo de pessoas que chegam a cidade nesse período, dinamizando os setores hoteleiro e alimentício. Além do circuito informal, como pôde ser constatado durante o trabalho de campo.

Por isso, para análise desse trabalho utilizou-se, também, o conceito de lugar proposto por Santos (1988), que afirma que "quanto mais os lugares se mundializam, mais se tornam singulares e específicos, isto é, únicos". Ele ressalta que "o lugar, aliás, define-se como funcionalização do mundo e é por ele (lugar) que o mundo é percebido empiricamente [...]”. (SANTOS, 2005, p. 158).

Santos (2008) trata sobre a "força do lugar" e qualifica como um espaço produzido por duas lógicas, a saber, a das vivências cotidianas e dos processos econômicos, políticos e 
sociais que constituem a globalização. É nesse sentido que, ao levar em conta esses processos, o lugar irá se diferenciar daquele interpretado pela Geografia Humanística.

Nota-se que os elementos da cultura de um povo são patrimônios também. Entendese neste estudo que cultura deve ser compreendida como algo intrínseco ao ser humano, tendo em vista que este ser é um ser social (LARAIA, 2001). Não existe ser humano sem cultura, e todos eles são capazes de aprender qualquer cultura, não importando suas origens. A cultura, nesse sentido, é observada como diretriz e formadora da visão de mundo de um indivíduo é aquilo que o ser humano constrói. As manifestações culturais e religiosas, assim, são entendidas como parte das culturas de um lugar, as festas são patrimônio e cultura. No caso da cidade de Bragança nota-se como à Festa de São Benedito é considerada uma das maiores representações da cultura do lugar.

Segundo Meneses (1992), é ainda importante considerar o uso cultural que se faz da cultura. Deve-se ultrapassar a barreira que neutraliza e reduz tal conceito. Para isso, é preciso "irrigar todo o tecido vivo da existência e fazer com que a ação cultural passe, precisamente, pelos terrenos mais importantes dessa mesma existência” (Idem, 1992, p. 97).

Nota-se, no caso da cidade de Bragança, que a Festa de São Benedito, juntamente com a marujada bragantina, são expressões patrimoniais e culturais do lugar. São elementos que resistem às pressões da vida urbana contemporânea ao longo desses mais de duzentos anos de história e tradição, onde essas práticas estão sendo passadas de geração em geração, fortalecendo assim os vínculos de pertencimento e identidade de um grupo.

Outro elemento importante que deve ser ressaltado quando se fala em patrimônio diz respeito à "ampliação da política patrimonial de conservação e administração" (CANCLINI, 1994, p. 96) do que foi estabelecido no passado aos usos sociais que incluem esses bens às necessidades contemporâneas da maioria e, por último, destaca-se que "o patrimônio de uma nação também se compõe dos produtos da cultura popular" (CANCLINI, 1994, p. 96). Logo não há como não pensar a dimensão patrimonial e cultural da Festa de São Benedito para aqueles que se identificam com a manifestação.

Para além dessas considerações é importante ter uma reflexão crítica no sentido de compreender que a ampliação do conceito de patrimônio cultural dentro das políticas públicas, também, vai propiciar benefícios para atividades econômicas mais recentes, como é o caso da atividade turística. Investe-se no fortalecimento e revalorização de áreas centrais como táticas que recriam conexões de identidade do grupo que ali vivem e das práticas 
culturais locais para usar como moeda de troca e isso pode ser algo muito perigoso e arriscado para as culturas se isso ocorrer sem planejamento e participação da sociedade local. Além disso, outro elemento é o "desvirtuamento ideológico e do sentido de valor social atribuído aos lugares" (COSTA, 2017, P. 68). Logo, entende-se que isto trata-se de uma inevitável consequência de como o capitalismo está sendo conduzido e tem causado consequências que afetam diretamente a cultura dos lugares.

Neste sentido, compreende-se que o patrimônio se constitui como uma "particularidade do espaço construída pelo tempo acumulado (num determinado lugar) apontando para um espaço-tempo próprio de um grupo e, nesta particularidade, é passível de ser consumido, portanto vendido, como fenômeno que distinguiria um sentido e um estilo para o consumo deste lugar (CARLOS, 2017, p. 27). Por isso, torna-se fundamental compreender os impactos da atividade turística sobre a cultura dos lugares lembrando que ela se trata também de uma atividade econômica, logo um de seus principais alvos é a reprodução do capital, e utilizar-se das singularidades do lugar pode ser uma estratégia vantajosa para ela, mas não necessariamente para aquele lugar.

É importante, também, ponderar o uso cultural que se faz da cultura, pois é preciso superar a barreira que neutraliza e reduz tal conceito como aponta Meneses (1992). Para que isso ocorra torna-se imprescindível "irrigar todo o tecido vivo da existência é fazer com que a ação cultural passe, precisamente, pelos terrenos mais importantes dessa mesma existência" (MENESES, 1992, p. 97).

\section{A FESTA DE SÃO BENEDITO EM BRAGANÇA-PA: PATRIMÔNIO E CULTURA DO LUGAR}

Bragança é uma cidade histórica que possui um patrimônio histórico representativo e marca a paisagem urbana da cidade fazendo dela uma das poucas cidades que ainda preserva/conserva parte do seu patrimônio na Amazônia. Porém, apenas uma parte destes patrimônios encontra-se amparada por instrumentos de preservação, no caso da cidade isso ocorre por meio dos tombamentos via decretos municipais e estaduais Lobato $(2014 ; 2017)$.

Para além do patrimônio histórico em Bragança observam-se manifestações de cunho religioso e outras de cunho cultural que expressam a relação que parte da população apresenta com o lugar. Dentre essas manifestações têm-se o círio de Nossa Senhora do Rosário, padroeira de Bragança, o Festival junino e a Festa de São Benedito. 
A Festa de São Benedito é uma manifestação religiosa e cultural que consiste no culto e devoção a São Benedito, que apesar de não ser o padroeiro oficial da cidade de Bragança, é considerado como tal por parte da população que se identifica com o "Santo Preto". Trata-se de uma festa que envolve, também, músicas e danças, sendo a mais famosa a marujada de São Benedito.

De acordo com Bordallo da Silva (1981) a origem comum da Marujada, figuras 04 e 05, com a Irmandade do Glorioso São Benedito de Bragança ocorreu quando no ano de 1798, os senhores consentiram o pedido dos escravos de organização de uma irmandade. Cumprida a primeira festa em louvor de São Benedito, os negros em sinal de consideração, incorporados, foram dançar de casa em casa dos seus benfeitores.

É no mês de dezembro que os três Santos: São Benedito da praia, São Benedito das colônias e São Benedito dos campos se reúnem na cidade de Bragança, a partir do dia dezessete, antes desse período os Santos já passaram por várias comunidades nas praias, nos campos e colônias de Bragança com as comitivas de esmolação levando os rituais de reza e cânticos para as famílias que acolhem os Santos e as comitivas em suas casas. Esse período das esmolações ocorre do mês de abril a dezembro e tem como um dos objetivos arrecadar donativos variados para serem leiloados no dia 26 de dezembro pela manhã.

Figura 04. Apresentação da Marujada de São Benedito em 26/12/2018

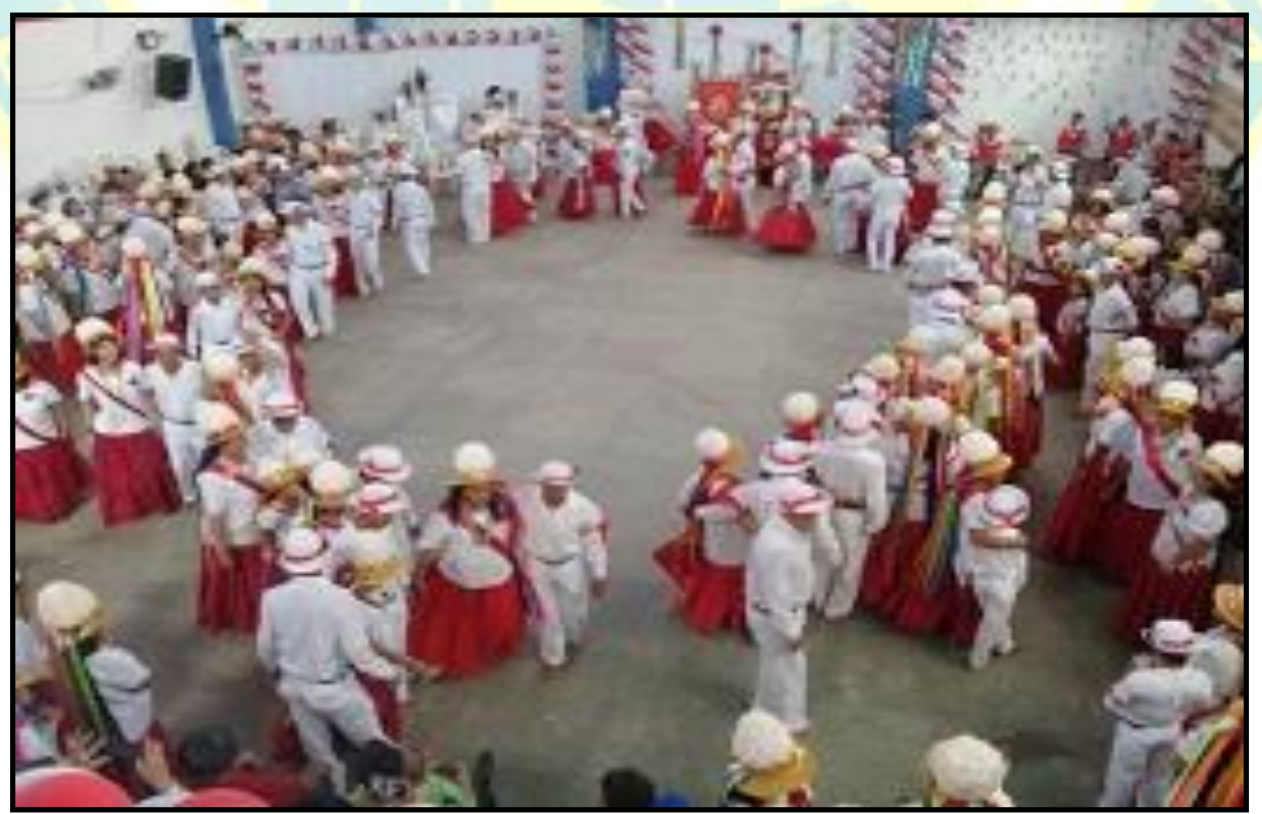

Fonte: Trabalho de campo. (Arquivo pessoal da autora). 
A Festa de São Benedito no mês de dezembro tem seu auge entre os dias 18 a 26 de cada ano, sendo o dia 26 marcada pela grande procissão pelas ruas da cidade de Bragança. No dia 25 a Irmandade do Glorioso São Bendito e outros marujos e marujas passam o dia em atividades como participação na missa pela manhã, logo após se reúnem para dançar a Marujada trajando roupas nas cores azul e branca, ao meio dia se dirigem para o local onde é ofertado um almoço para eles pelo juiz ou pela juíza da festa daquele ano. Vale ressaltar que a transformação da Irmandade de cunho religioso em organização civil fortaleceu a Marujada, ganhando força e destaque o sentido de caracterizar a festa de São Benedito (SILVA, 1997).

Observou-se que durante o dia 25 de dezembro as marujas e marujos permanecem o dia todo no Complexo de São Benedito, que compreende a praça reunindo a Igreja de São Benedito, o teatro museu da Marujada (figura 05), e o barracão da Marujada (figura 06). Nessa data, os participantes da manifestação encerram o dia dançando no barracão.

Figura 05: Teatro - museu da Marujada de Bragança

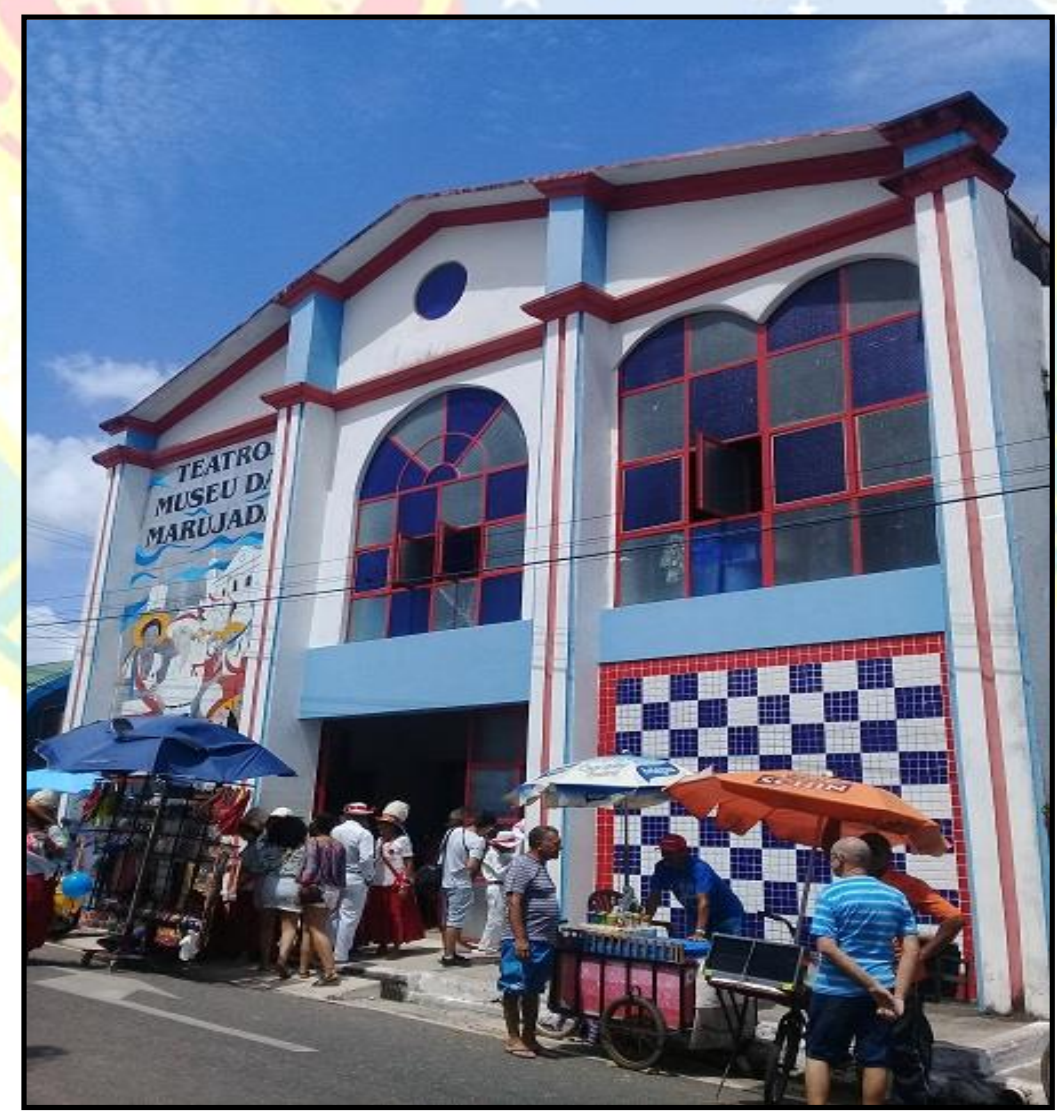

Fonte: Trabalho de campo. Fonte: Arquivo pessoal da autora. 
Figura 06: Antigo barracão da Marujada em Bragança-PA

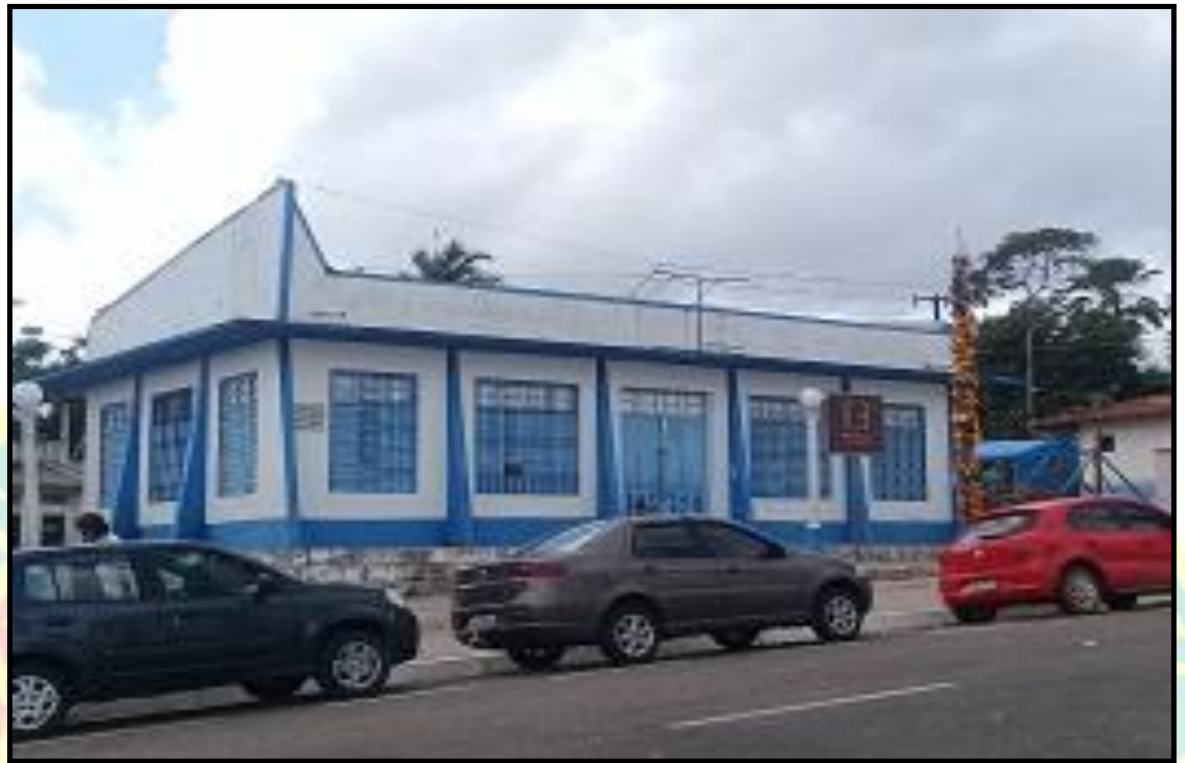

No dia 26 de dezembro é o dia considerado auge da Festa de São Benedito, pois é o dia da procissão que sai da igreja de São de Benedito e percorre algumas ruas da cidade. É o momento de maior concentração de devotos, turistas e visitantes durante todo o período da festa. De acordo com estatísticas da polícia militar a estimativa é que o dia da procissão consegue reunir mais de 50.000 mil pessoas. Trata-se de um dia marcado por várias atividades, durante a manhã ocorre o leilão, enquanto isso os marujos e marujas dançam a Marujada no Teatro Museu até por volta de 11h30min. Em seguida, eles se encaminham para o tradicional almoço ofertado pelos juízes da festa. E à tarde, por volta das 16 horas, começa a procissão pelas ruas do centro da cidade.

Muitos devotos participam da procissão vestidos a caráter, no dia 26 de dezembro as mulheres vestem-se com blusas brancas e saias vermelhas e os homens com calças e camisas brancas e alguns detalhes em vermelho, uma referência a São Benedito. No dia anterior a vestimenta dos marujos e marujas é diferente, mulheres vestem-se com blusas brancas e saias azuis e homens calças e blusas brancas e com detalhes em azul, é uma referência ao menino Jesus.

O dia 26 de dezembro, dia da procissão para o São Benedito é um momento muito aguardado por parte significativa da população bragantina. Muitas pessoas de outros municípios próximos, também, chegam à cidade para participar e pagar suas promessas. 
Trata-se de um tempo para receber familiares e amigos que moram em outros lugares do Estado do Pará e do país, bem como, é um período marcado por um fluxo intenso de turistas internacionais, nacionais e regionais que chegam à Bragança para conhecer essa festa.

Durante o trabalho de campo para essa pesquisa, foram realizadas algumas entrevistas para compreender a dinâmica da festa de São Benedito e a relação dela com o patrimônio e a cultura do lugar.

É um dos períodos do ano que o setor hoteleiro mais se dinamiza. Entretanto, notouse através das entrevistas realizadas durante o trabalho de campo, que a rede hoteleira ainda precisa melhorar alguns serviços, um deles é a oferta de leitos, constatou-se que alguns hotéis não tinham mais vagas para o período da festa. É necessário pensar em alguma estratégia capaz de contemplar os turistas que chegam à Bragança para conhecer e participar da Festa de São Benedito.

Foi possível constatar através das várias falas dos moradores locais entrevistados que há uma forte relação de pertencimento daquela festa, do fazer parte daquele momento, pois há um forte envolvimento e devoção por parte dos marujos e marujas. Quando questionados sobre a importância da Festa de São Benedito para Bragança, todos os entrevistados afirmaram ser uma manifestação de grande importância para o município, alguns chegaram até mesmo a mencionar que a Festa de São Benedito para eles é até mais importante do que a Festa da padroeira oficial Nossa Senhora do Rosário. Todos entrevistados afirmaram, também, considerar a Festa de São Benedito, em especial, a Marujada, como patrimônio cultural de Bragança ${ }^{2}$.O poder público municipal, por meio das secretarias de turismo e de cultura, também ressaltara durante as entrevistas a importância da Festa de São Benedito para o município.

\begin{abstract}
Entendemos que a Festa de São Benedito é um elemento fundamental da cultura do bragantino [...] Já fizemos várias ações com o objetivo de valorizar a festa, já tivemos edital comtemplado pra desenvolver o turismo religioso. Há uma boa parceria entre a Irmandade e a prefeitura. Nós sempre que podemos apoiamos, porque sabemos a importância da festa, pra ser divulgada e conhecida por mais pessoas. (Técnicos das Secretarias de Cultura e de Turismo da Prefeitura de Bragança. Trabalho de campo realizado entre os dias 18 e 26 de dezembro de 2018).
\end{abstract}

Em síntese, o que se analisou durante o trabalho de campo é que a Festa de São Benedito é um patrimônio cultural do lugar e é reconhecido por grande parte da população

\footnotetext{
${ }^{2}$ Para essa pergunta a entrevistadora explicava o que era patrimônio cultural e depois perguntava se o entrevistado considerava a Festa de São Benedito juntamente com a Marujada como patrimônios culturais de Bragança. 
como um elemento cultural de grande relevância tanto na escala local e regional. É perceptível, também, que a Festa é um elemento atrativo para o turismo cultural.

A Festa já possui mais de duzentos anos de história e tradição, como mencionado anteriormente, e a cada ano o número de participantes aumenta, principalmente, no dia da procissão em homenagem a São Benedito, no dia 26 de dezembro e de outros momentos que compõem a Festa, de acordo com dados divulgados pelos meios de comunicação locais e estadual $^{3}$.

Outro elemento que precisa ser destacado é quanto a economia, durante os dias de Festa e até mesmo no período que antecede a mesma, o comércio fica mais ativo, os hotéis ficam com suas reservas mais preenchidas, bem como os bares e restaurantes locais. Os entrevistados, ressaltaram que há um aumento considerável das vendas, tudo isso em decorrência do período festivo.

\section{CONSIDERAÇÕES FINAIS}

Ao longo da pesquisa percebeu-se que a Festa de São Benedito é uma das maiores manifestações religiosas e culturais da região nordeste do Estado do Pará. No caso do município de Bragança é a maior expressão cultural e patrimonial que vem sendo passada de geração em geração, através das expressões culturais, ritos, rituais, danças, fé e devoção expressos na Festa de São Benedito.

Uma manifestação que chegou nos seus 220 anos de história e tradição no ano de 2018, que resiste ao tempo e que a cada ano ganha mais adeptos e devotos. Famílias que se reúnem para louvar e dançar em homenagem ao Santo Preto, pessoas que acreditam no poder da fé em São Benedito. Turistas, também, que se encantam com as formas, cores, sabores, ritos que envolvem a Festa em homenagem a São Benedito.

Observou-se que há uma forte relação econômica, mas também social e cultural entre o patrimônio e a cultura em Bragança, haja vista que a Festa de São Benedito, e em especial a Marujada, promove uma relação de identidade de parte da população com o lugar. Trata-se de um patrimônio vivo, marcado por singularidades e particularidades do lugar.

\footnotetext{
${ }^{3}$ A festa em homenagem a São Benedito, em Bragança, no Nordeste do Pará, recebe o nome de marujada por ser organizada, desde 1798, pela Irmandade da Marujada (que uma marujada ou conjunto de marujos). A festividade começa com uma missa campal em frente à Paróquia São Benedito. A festa termina com uma procissão com a imagem do padroeiro por algumas ruas da cidade. A estimativa é que mais de 50 mil pessoas participem da festa. Fonte: http://romariabrasil.com.br/2017/03/braganca-pa/
} 
Além disso, trata-se de uma manifestação que contribui com a geração de divisas para o município, contribui com a criação de empregos e rendas para alguns setores como o turismo, o alimentício, entre outros.

\section{REFERÊNCIAS BIBLIOGRÁFICAS}

BORDAllo DA SILVA, Armando. Contribuição ao Estudo do Folclore Amazônico na Zona Bragantina. Belém: Falângola, 1981.76p.

CANCLINI, N. G. O patrimônio Cultural e a Construção do Imaginário Nacional. Revista do Patrimônio Histórico e Artístico Nacional, no 23, p. 95-115, 1994.

CARLOS, Ana F. Turismo e patrimônio: um aporte geográfico. In: (Orgs.) PAES, M. T. D.; SOTRATTI, M. A. GEOGRAFIA, TURISMO E PATRIMÔNIO CULTURAL identidades, usos e ideologias..São Paulo: Annablume, 2017. Capítulo 2, p. 27-42.

CARVALHO, G. M. de O. A festa do "Santo Preto": tradição e percepção da Marujada Bragantina. Dissertação de Mestrado em Desenvolvimento Sustentável. Universidade de Brasília, Brasília, 2010. $165 \mathrm{f}$.

IBGE. Biblioteca Digital do IBGE. Disponível em: http://biblioteca.ibge.gov.br/visualizacao/fotografias/GEBIS\%20-\%20RJ/PA8607.jpg). Acesso em: 20 de outubro de 2013.

LARAIA, R.B.Cultura: um conceito antropológico. Rio de Janeiro: Jorge Zahar Ed., 2001. 120p.

LOBATO, A. S.Turismo, patrimônio cultural e produção do espaço: uma análise do centro histórico da cidade de Bragança-PA. Dissertação de Mestrado em Geografia. Universidade Federal do Pará, Belém, 2014. $176 \mathrm{f}$.

LOBATO, A. S. A Festividade de São Benedito de Bragança no Estado do Pará: uma analise sobre o patrimônio e a identidade Bragantina. In: XII ENANPEGE, 12., Porto Alegre, 2017.Anais do XII ENANPEGE. Porto Alegre: ENANPEGE, 2017. pp. 1-10

MACHADO, D. C.; PIRES, M. J. Turismo e patrimônio cultural imaterial: a capoeira em SalvadorBA. In: COSTA, E. B.; BRUSADIN, L. B.; PIRES, M. do C. (Org.). Valor patrimonial e turismo: limiar entre história, território e poder. São Paulo: Outras Expressões, 2012. Capítulo 14, p. 245-260.

MENESES, Ulpiano. "O Patrimônio Cultural entre o Público e o Privado". In: O direito à Memória: patrimônio histórico e cidadania. São Paulo: Departamento do Patrimônio Histórico, Secretaria Municipal da Cultura, 1992.

NONATO DA SILVA, D. B. R. Os Donos de São Benedito: convenções e rebeldias na luta entre o catolicismo tradicional e devocional na cultura de Bragança, século XX. Dissertação de Mestrado em História Social da Amazônia. Universidade Federal do Pará, Belém, 2006. 202 f.

PAES, Maria T. D. Patrimônio cultural, turismo e identidades territoriais um olhar geográfico. In: BARTHOLO, R; BURSZTYN, I; SANSOLO, D. (Org.). Turismo de Base Comunitária diversidade de olhares e experiências brasileiras. Rio de Janeiro: Ed. Letra e Imagem, 2009. Capítulo 09, p. 162176. 
SANTOS, M. Metamorfose do Espaço Habitado. São Paulo, Hucitec, 1988. 124p.

SANTOS, M. Da totalidade ao lugar. São Paulo: Edusp, 2005. 176p.

SANTOS, M. A Natureza do Espaço. São Paulo: EDUSP, 2008. 236p.

SILVA, D. B. da. Os tambores da esperança: Um estudo sobre cultura, religião, simbolismo e ritual na festa de São Benedito da cidade de Bragança. Belém: Falângola, 1997.302p.

TUAN, Y. -F. Espaço e Lugar: a perspectiva da experiência. São Paulo: DIFEL, 1983. 248p.

Trabalho enviado em: 23/01/2019

Trabalho aceito em: 12/03/2019

Revista do Instituto Histórico e Geográfico do Pará (IHGP), (ISSN: 2359-0831 - online), Belém, v. 05, n. 02, p. 140-155, jul./dez. 2018. 